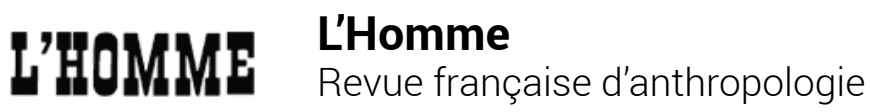

175-176 | juillet-septembre 2005

Vérités de la fiction

\section{Liliane Bodson, ed, La Migration des animaux: connaissances zoologiques et exploitations anthropologiques selon les espèces, les lieux et les époques}

Liège, Université de Liège, 2004, Liège, XIX + 234 pages

Jean-Pierre Digard

\section{OpenEdition}

Journals

Édition électronique

URL : http://journals.openedition.org//homme/2053

DOI : 10.4000/lhomme.2053

ISSN : 1953-8103

Éditeur

Éditions de l'EHESS

Édition imprimée

Date de publication : 15 octobre 2005

Pagination : 507-508

ISBN : 2-7132-2035-1

ISSN : 0439-4216

\section{Référence électronique}

Jean-Pierre Digard, «Liliane Bodson, ed, La Migration des animaux : connaissances zoologiques et exploitations anthropologiques selon les espèces, les lieux et les époques », L'Homme [En ligne], 175-176 | juillet-septembre 2005, mis en ligne le 30 novembre 2006, consulté le 21 septembre 2020. URL : http://journals.openedition.org/lhomme/2053 ; DOI : https://doi.org/10.4000//homme.2053 


\title{
Liliane Bodson, ed, La Migration des animaux : connaissances zoologiques et exploitations anthropologiques selon les espèces, les lieux et les époques
}

\author{
Liège, Université de Liège, 2004, Liège, XIX + 234 pages
}

Jean-Pierre Digard

\section{RÉFÉRENCE}

Liliane Bodson, ed. La Migration des animaux : connaissances zoologiques et exploitations anthropologiques selon les espèces, les lieux et les époques. Liège, Université de Liège, 2004, Liège, XIX + 234 p., bibl., index, ill., fig., tabl., cartes (« Colloques d'histoire des connaissances zoologiques »15).

1 POURSUIVANT inlassablement son entreprise de «Colloques d'histoire des connaissances zoologiques", la très savante Liliane Bodson, historienne de l'Antiquité classique à l'université de Liège, livre aujourd'hui le volume des actes de la quinzième réunion (tenue le 22 mars 2003), qui fut consacrée aux migrations des animaux.

Deux textes particulièrement substantiels, qui tiennent plus du mémoire que de la communication, ouvrent le volume. Le premier, fort de quarante-sept pages imprimées et de multiples cartes et figures, dû à Guy Jarry, dresse l'histoire et le tableau des connaissances sur les migrations des oiseaux. On y apprend notamment que celles-ci ne furent pas reconnues par les naturalistes avant la fin du XVIII ${ }^{e}$ siècle. Dans le second, de trente-cinq pages, Marie-Christine Marinval traite, elle, des migrations des poissons, mais dans une autre perspective, à la fois microrégionale (dans le bassin versant de la Loire) et macrohistorique (de la fin de la dernière glaciation jusqu'à nos jours). Elle montre qu'avec le réchauffement climatique de la fin du Tardiglaciaire, des poissons d'espèces nouvelles et anciennes sont venus peupler ou repeupler les eaux douces, 
avec, parmi ces derniers, des animaux migrateurs comme le saumon, l'esturgeon ou l'anguille, que les populations riveraines ont peu à peu appris à exploiter.

3 Viennent ensuite trois textes d'histoire culturelle. Étudiant ce que les encyclopédistes médiévaux, d'Isidore de Séville à Jean Corbéchon (xIV siècle), ont écrit sur les migrations animales, Jacques Voisenet conclut que les connaissances de ces auteurs sont encombrées de croyances (comme celle aux éléphants migrant vers le Paradis terrestre pour s'accoupler) qui ne laissent guère de place à l'observation. S'interrogeant sur le goût des peintres flamands des XVI ${ }^{\mathrm{e}}$ et XVII $\mathrm{X}^{\mathrm{e}}$ siècles pour les formes et les couleurs des papillons exotiques, Vincent Fagniart cherche où ces artistes ont trouvé leurs modèles: sources livresques, exemplaires naturalisés, mais aussi Lépidoptères migrateurs estivant en Belgique comme le vulcain (Vanessa atalanta), le plus fréquemment représenté dans les tableaux. Puis Marianne Mesnil et Assia Popova étudient, en folkloristes, les signes annonciateurs du printemps dans les Balkans, parmi lesquels le retour des oiseaux migrateurs, comme la cigogne et l'hirondelle, à qui l'on offre l'«amulette de mars » en échange d'un espoir de bonheur et de bonne santé durant la belle saison.

4 Explorant les confins du phénomène des migrations animales, les deux communications suivantes débouchent sur des conclusions moins convenues. Jacqueline Milliet considère la "migration forcée " (l'introduction) de chiens par l'homme en Nouvelle-Calédonie, en Tasmanie et dans les monts Everard en Australie. La diversité des destins de ces canidés, compagnons des humains ici, animaux errants là, parias ailleurs encore, illustre la complexité et la flexibilité du phénomène de la domestication animale. Georges Métailié s'intéresse, lui, à l'attention qui a toujours été portée, en Chine ancienne, aux diverses mutations et transformations animales. Certains changements (de la caille en hamster ou de l'épervier en coucou) ont été expliqués par des auteurs chinois comme le résultat de comportements semblables, notamment quant aux déplacements saisonniers.

5 Enfin, Laurence Denooz analyse une fable philosophique dans laquelle un auteur égyptien moderne, Tawfiq al-Hakim (1898-1937), compare le comportement des grives en période migratoire à celui des humains sur la route des vacances. De cette allégorie animalière, il tire une leçon: celle d'un nécessaire équilibre entre rationalité et spiritualité afin d'atteindre al-insâniyya, un stade supérieur de l'humanité.

Ce volume est composé avec le soin habituel, avec des résumés en français et en anglais, et trois index (des noms français d'animaux, des noms scientifiques d'animaux et des noms d'auteurs). Il laisse cependant, quant à sa composition, une impression d'hétérogénéité et de déséquilibre. Sans doute était-il nécessaire de considérer la notion de migration dans une acception large, d'où la présence, si profitable, de ces « chiens migrateurs » et de ces « mutants » chinois; mais on s'explique mal, du coup, l'absence d'espèces comme le renne, dont les migrations sont des plus intéressantes. $\mathrm{Au}$ total, l'apport de l'ensemble à l'anthropologie est modeste, en dépit - ou à cause ? - de l'introduction, à l'érudition massive, presque étouffante, de Liliane Bodson. Mais on peut aussi considérer qu'il est plus sage d'attendre de disposer de la totalité de ces "Colloques d'histoire des connaissances zoologiques", qui représentent déjà une somme considérable, pour essayer valablement d'en tirer des enseignements de portée générale. Attendons donc... 